\title{
ELECTRON MICROSCOPY OF ANIONIC SURFACTANT-DIRECTED SYNTHESIS OF MAGNETITE NANOPARTICLES
}

\author{
Sharali Malik ${ }^{\mathrm{a}^{*}}$, Ian James Hewitt ${ }^{\mathrm{b}}$, Annie Katherine Powell ${ }^{\mathrm{a}, \mathrm{b}}$ \\ ${ }^{a}$ Institute of Nanotechnology, Karlsruhe Institute of Technology, North Campus, Karlsruhe D-76021, Germany \\ ${ }^{b}$ Institute of Inorganic Chemistry, Karlsruhe Institute of Technology, South Campus, Karlsruhe D-76131, Germany \\ "e-mail:sharali.malik@kit.edu
}

\begin{abstract}
Here we report new work on the synthesis and an electron microscopy study of the earliest known magnetic material, magnetite $\left(\mathrm{Fe}_{3} \mathrm{O}_{4}\right)$. We have synthesized a variety of magnetite nanoparticles which appear to have biogenic signatures and could give insights into how the nanomagnetite in biological systems forms, and how they may be associated with Alzheimer's disease. We have also synthesized mesoporous magnetite nanoparticles which have potential use in the targeted drug delivery.
\end{abstract}

Keywords: magnetite, magnetic nanoparticles, hydrothermal synthesis, drug delivery.

Received: October 2015/ Revised final: December 2015/ Accepted: December 2015

\section{Introduction}

Magnetite $\left(\mathrm{Fe}_{3} \mathrm{O}_{4}\right)$ in the form of lodestone is the original magnetic material used by mankind to navigate the Earth by following geomagnetic field lines. It is also used for navigation in Nature by honey bees, homing pigeons and bacteria. Currently, magnetic nanoparticles are used for data storage, magnetic resonance imaging (MRI) and are the potential colloidal mediators for cancer magnetic hyperthermia. This area of nanotechnology spans the boundaries of chemistry, biology, medicine and materials science.

The earliest reported medical use of magnetite powder for internal applications was in the 11th century A.D. by the Persian physician and philosopher Avicenna of Bokhara [1,2]. Today magnetic nanoparticles are used for magnetic resonance imaging (MRI) and as colloidal mediators for magnetic hyperthermia cancer treatment [3].

In 1992, it was reported that magnetite $\left(\mathrm{Fe}_{3} \mathrm{O}_{4}\right)$ is present in the human brain [4] and more recently that nanoscale biogenic magnetite is associated with neurodegenerative diseases such as Alzheimer's [5]. Although this association was first discovered over fifty years ago by Goodman [6], to date the magnetite's origin and formation are not certain. Here we show that the synthesis of magnetite in the presence of the surfactant sodium dodecyl sulphate (SDS) gives rise to a variety of nanoscale morphologies, some of which look remarkably similar to magnetite found in organisms, suggesting that similar processes may be involved. Furthermore, these $0 \mathrm{D}$ materials with nanoscale dimensions and with the potential to show quantum confinement effects are of interest in the areas of biosensors [7], biomedical imaging [8] and as tunneling magnetoresistance (TRM) sensor elements in magnetic random access memory (MRAM) configurations, which can be used to form magnetic, programmable biochips [9].

In the more extensively studied magnetotactic bacteria [10], biogenically controlled morphologies of magnetite, which normally crystallises in a cubic space group, occur in the form of nanocrystals. These have been found to have elongated $\{111\}$ axes often with rhombic or truncated dodecahedral morphology. They are part of intracellular structures called magnetosomes [11], which consist of a nanocrystal surrounded by a lipid bilayer membrane. They arrange in a 1D array to form a "compass needle", which is utilised by the bacteria to sense the Earth's magnetic field $[12,13]$. Figure 1 shows two typical examples of these magnetotactic bacteria [14].

Taking this lead from biology, where the biogenic templates produce magnetite of defined shapes and sizes, we have been interested in investigating how surfactant molecules could similarly influence magnetite formation.

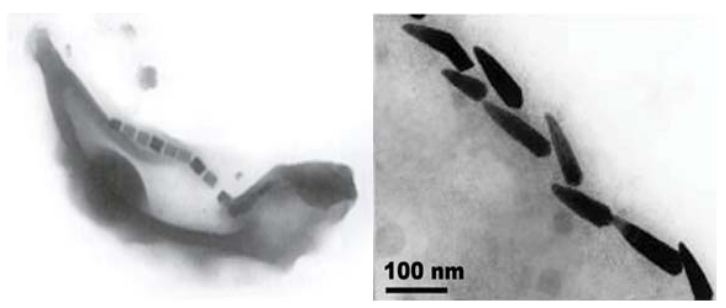

Figure 1. Two examples of magnetite in magnetotactic bacteria. Left: Magnetospirillum magnetotacticum (whole organism) showing the location of magnetoite crystals and Right: an example of a string of bulletshaped crystals within a magnetotactic bacterium [14], Copyright (2008) Federation of European Microbiological Societies.

Presented at the XVIII-th International Conference "Physical Methods in Coordination and Supramolecular Chemistry"

(Dedicated to the memory of the professor Constantin Turta and professor Mihail Revenco), 8-9 October 2015, Chisinau, Republic of Moldova 


\section{Experimental \\ Materials}

All chemicals were reagent grade and used without further purification. Ferrous chloride tetrahydrate $\left(\mathrm{FeCl}_{2} \cdot 4 \mathrm{H}_{2} \mathrm{O}>99 \%\right)$, sodium hydroxide $(\mathrm{NaOH}>97 \%)$ and sodium dodecyl sulphate $(\mathrm{SDS}>99 \%)$ were purcheased from Sigma-Aldrich. Double distilled water, sodium hydroxide solutions and SDS solutions were deoxygenated by bubbling through $\mathrm{N}_{2}$ gas for $1 \mathrm{~h}$ prior to use. The synthesis of magnetite was performed under nitrogen in an autoclave using a $20 \mathrm{~mL}$ Teflon insert.

Compounds 1-5 preparation

To an aqueous solution containing $\mathrm{FeCl}_{2} \cdot 4 \mathrm{H}_{2} \mathrm{O}$ and $\mathrm{SDS}$, a deoxygenated aqueous $\mathrm{NaOH}$ solution was added (Table 1). The autoclave was heated to $200^{\circ} \mathrm{C}$ for $24 \mathrm{~h}$ and after cooling the magnetite was isolated as detailed below.

Table 1

Reagent quantities and concentrations used to prepare compounds 1-5.

\begin{tabular}{cccc}
\hline Compound & $\mathrm{FeCl}_{2} \cdot 4 \mathrm{H}_{2} \mathrm{O}(0.2 \mathrm{M})$ & $\mathrm{NaOH}(1 \mathrm{M})$ & $\mathrm{SDS}$ \\
\hline 1 & $5.0 \mathrm{~mL}$ & $2.0 \mathrm{~mL}$ & $0.5 \mathrm{~mL}(15 \mathrm{mM})$ \\
2 & $5.0 \mathrm{~mL}$ & $1.0 \mathrm{~mL}$ & $2.0 \mathrm{~mL}(15 \mathrm{mM})$ \\
3 & $5.0 \mathrm{~mL}$ & $1.0 \mathrm{~mL}$ & $0.5 \mathrm{~mL}(35 \mathrm{mM})$ \\
4 & $5.0 \mathrm{~mL}$ & $1.0 \mathrm{~mL}$ & $0.5 \mathrm{~mL}(35 \mathrm{mM})$ \\
5 & $5.0 \mathrm{~mL}$ & $1.0 \mathrm{~mL}$ & $0.5 \mathrm{~mL}(35 \mathrm{mM})$ \\
\hline
\end{tabular}

The suspended magnetite/surfactant product was put in a sonication bath (Qualilab USR-30 H) for $1 \mathrm{~h}$. The suspension was then diluted with a 20 fold excess of distilled water before being sonicated again for 10 min and centrifuged (Heraeus Instruments, Labofuge 400) at $3500 \mathrm{rcf}$ for $30 \mathrm{~min}$. The samples containing particles less than $100 \mathrm{~nm}$ in size were filtered (NC10; Schleicher \& Schuell) prior to sonication and centrifugation. The magnetite sediment was suspended in ethanol and sonicated for a few seconds and then "spotted" onto carbon coated copper grids of 400 mesh size for TEM examination and onto $1 \mathrm{~cm}$ squares of polished silicon wafers for SEM examination and then dried before analysis.

Equipment

Scanning electron microscopy (SEM) was performed using a LEO 1530 scanning electron microscope operating at $3 \mathrm{KeV}$. Transmission electron microscopy (TEM) measurements were performed using a Tecnai T20 ST transmission electron microscope operating at $200 \mathrm{KeV}$.

\section{Results and discussion}

In the course of our experiments, we found that hydrothermal conditions can be used to produce octahedral magnetite (Figure 2) as typically observed under geological conditions (Figure 3).

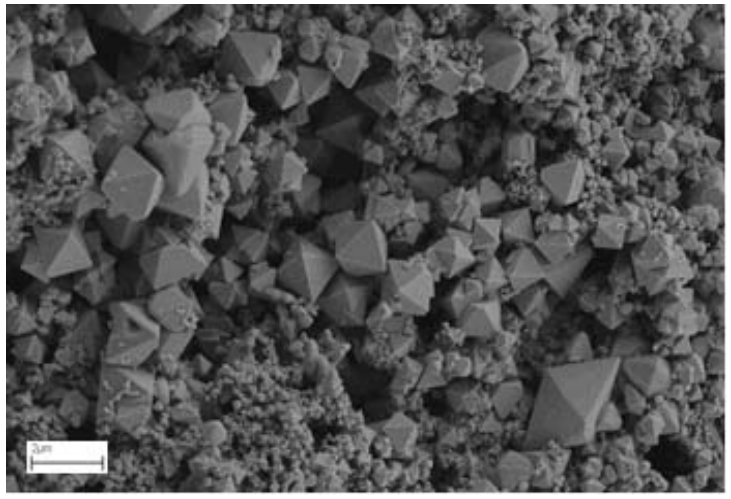

Figure 2. Octahedrally shaped magnetite. SEM of magnetite formed hydrothermally without SDS present.

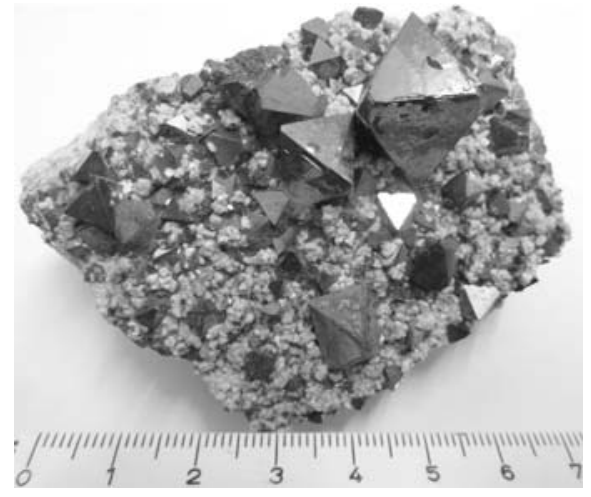

Figure 3. Geological octahedrally shaped magnetite crystallised on feldspar and quartz found in Bolivia (photo by S. Malik).

However, when SDS (Figure 4) is present, we found instead a variety of magnetite morphologies, which appear to have biogenic trademarks. SDS (Figure 4) is commonly used to mimic hydrophobic binding environments such as cell membranes [15] and has been used to study the folding and thermal stability of cytochrome c (cyt c), which is a biologically important electron transfer system [16]. 


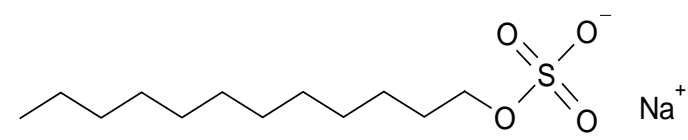

Figure 4. The anionic surfactant SDS.

The synthesis of magnetite in the presence of SDS under hydrothermal conditions yielded a variety of magnetite morphologies, as revealed by SEM and TEM. We discuss five of these morphologies here.

Firstly, bullet shaped needles with an aspect ratio of 1:6-8 and 1-2 $\mu \mathrm{m}$ in length with square-pyramidal endings (system 1, Figure 5) can be observed as aligned bundles and rather unusually these crystals frequently grow with a $90^{\circ}$ bend. Acicular magnetite and maghemite with similar aspect ratios and sizes are commonly used for magnetic media devices. However, the route of synthesis of these crystallites is not straightforward and typically involves the synthesis of goethite $(\alpha-\mathrm{FeOOH})$ or lepidocrocite $(\gamma-\mathrm{FeOOH})$, followed by dehydration to form hematite $\left(\alpha-\mathrm{Fe}_{2} \mathrm{O}_{3}\right)$ and then reduction to magnetite. Then, this can be re-oxidised to give maghemite $[17,18]$.

Arrays of magnetite octahedra (system 2, Figure 6) were observed having 80-100 nm dimensions and forming $1 \mathrm{D}$ stacks of up to $4 \mu \mathrm{m}$ in length. In 2008, Schumann et al. reported magnetofossils derived from magnetotactic bacteria which, as seen from their SEM images and drawings depicted in Figure 7, show similar morphological features with spearhead-like magnetite particles.

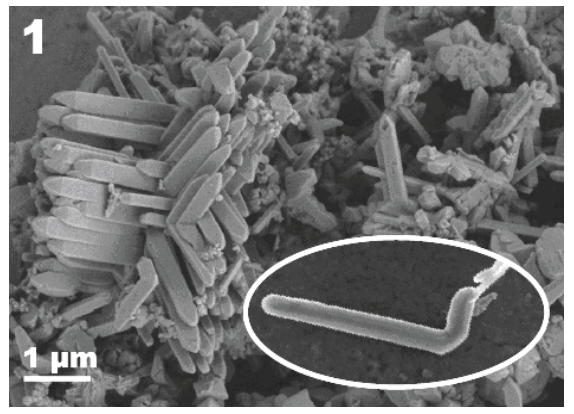

Figure 5. Bullet shaped needles which are frequently observed with a $90^{\circ}$ bend.

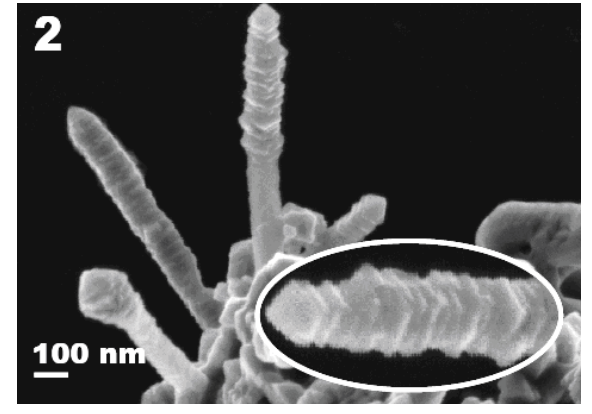

Figure 6. SEM of ordered 1D array of nanocrystallites.
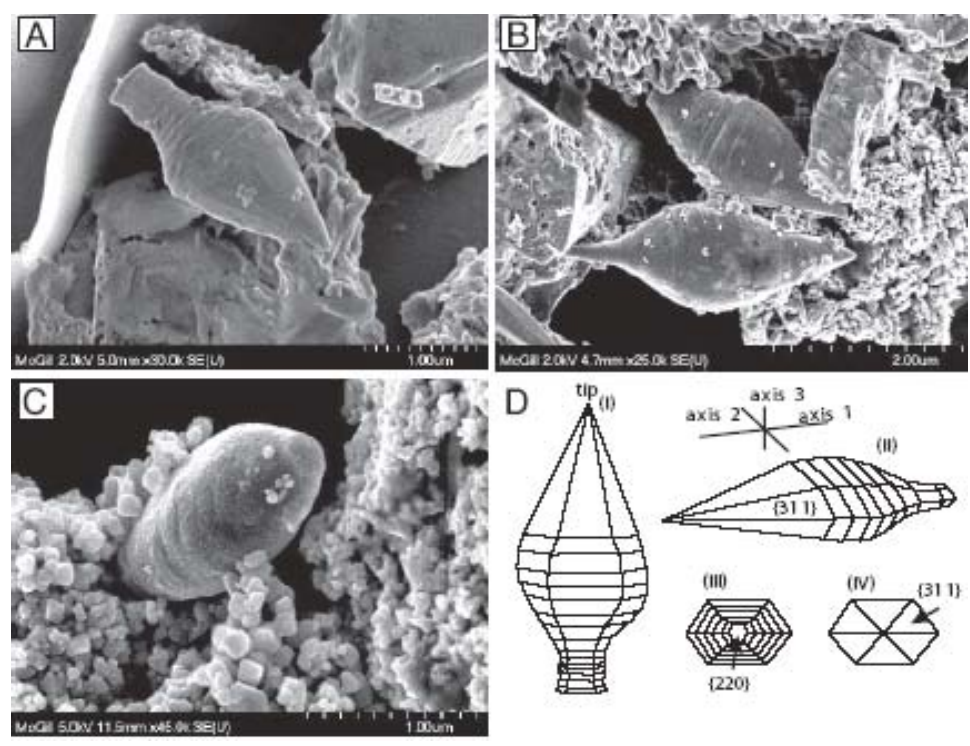

Figure 7. Magnetofossils derived from magnetotactic bacteria [19]. Copyright (2008) National Academy of Sciences, USA.

Whiskers with an aspect ratio of 1:10 (system 3, Figures $8(a)$ to (d)), typically around 100-200 nm in length, are also formed and they self-assemble into 2D hexagonal plates and 3D "flower" motifs. 


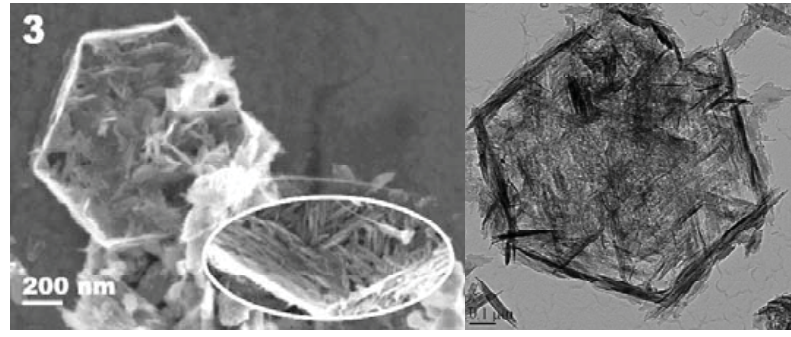

(a)

(b)

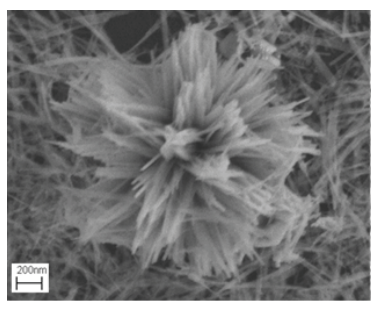

(c)

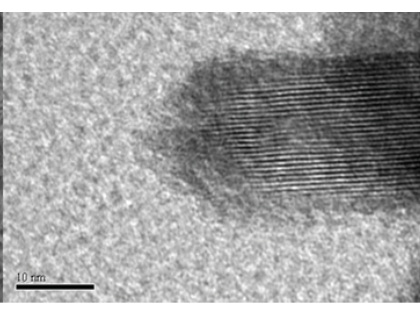

(d)

Figure 8. (a) SEM overview and detail (inset);

(b) TEM overview of whiskers forming 2D hexagonal plate motifs;

(c) SEM overview of magnetite whiskers in 3D flower motifs;

(d) TEM detail of whisker tip.

String-like crystallite assemblies are observed (system 4, Figure 9) with the strings composed of nanocrystals less than $10 \mathrm{~nm}$ in diameter arranged in helical bundles of 70-200 nm in diameter and up to $5 \mu \mathrm{m}$ in length. These are reminiscent of the magnetite spheres reported by Hou et al. [20], which were prepared hydrothermally by reducing $\left[\mathrm{Fe}(\mathrm{acac})_{3}\right]$ in the presence of various surfactants, and is the only other report of such an unusual form of magnetite produced hydrothermally. Finally, mesoporous nanocrystallites form (system 5, Figure $10(a)$ and (b)) with diameters of 40-100 nm and morphology similar to the widely reported truncated dodecahedral shape seen in certain magnetotactic bacteria [12]. These nanocrystallites, as observed for system 3, also seem to self-align. The "question-mark" motif seen in Figure $10(a)$ is typical.

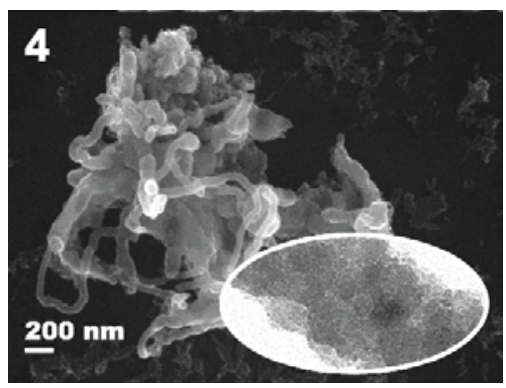

Figure 9. SEM of string-like assemblies composed of nanocrystallites (the insert shows a TEM image).

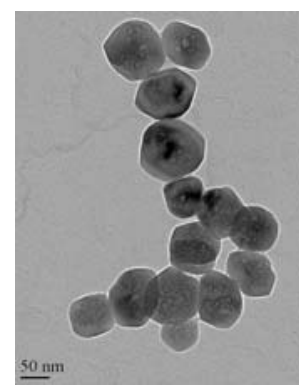

(a)

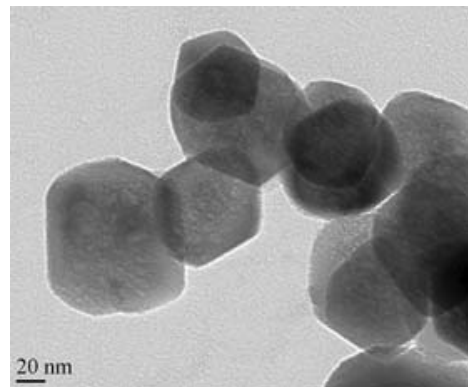

(b)
Figure 10. (a) TEM overview and (b) TEM detail of mesoporous magnetite nanocrystallites.

It has been reported that magnetosome vesicles are present before magnetite formation in magnetotactic bacteria [21] and we can draw a parallel to this situation given the presence of SDS micelles providing a reaction space for formation of nanocrystalline magnetite arrays. In addition to its "biogenic signature", this mesoporous nanomagnetite may prove useful for targeted drug delivery [22].

\section{Conclusions}

In Nature, the synthesis of the bacterial magnetosome seems to be a complex process that involves several discrete steps, including magnetosome vesicle formation, iron uptake by the cell, iron transport into the magnetosome vesicle and controlled $\mathrm{Fe}_{3} \mathrm{O}_{4}$ biomineralization within the magnetosome vesicle. In general, there has been little research regarding the methods by which bacteria synthesize these mineral crystals in specific morphologies.

In our experiments, we have shown that the synthesis of magnetite in the presence of the surfactant sodium 
dodecyl sulphate gives rise to a variety of nanoscale morphologies, some of which look remarkably similar to magnetite found in organisms, suggesting that similar morphological control processes may be involved.

Furthermore, these 0D materials with nanoscale dimensions are of interest in the areas of biosensors and biomedical imaging. The magnetite whiskers, in particular, are ideally suited for use in "lab-on-a-bead" devices, which have whisker morphology and are set to be the next-generation lab-on-a-chip devices. They are both cheaper and better suited to use in field diagnostics and theranostics. In addition, the whiskers are the ideal shape for use as tunneling magnetoresistance (TRM) sensor elements in magnetic random access memory (MRAM) configurations, which can be used to form magnetic, programmable biochips.

\section{Acknowledgements}

The authors would like to thank the D.F.G. Center for Functional Nanostructures for financial support. They would also like to thank Harald Rösner (now at University of Münster) for assistance with the TEM. This work is part of COST Action TD1402 "Multifunctional Nanoparticles for Magnetic Hyperthermia and Indirect Radiation Therapy (RADIOMAG)“.

\section{References}

1. Avicenna (Abu Ali Sina). The Canon of Medicine, 1025, 510 p. https://archive.org/stream/ AvicennasCanonOfMedicine/9670940-Canon-of-Medicine\#page/n0/mode/2up

2. Andrä, W.; Nowak, H. Eds. Front Mater, in Magnetism in Medicine: A Handbook. Second Edition. Wiley-VCH Verlang GmbH \& Co. KGaA: Weinheim, Germany. 2007, doi: 10.1002/9783527610174.fmatter.

3. Mornet, S.; Vasseur, S.; Grasset, F.; Veverka, P.; Goglio, G.; Demourgues, A.; Portier, J.; Pollert, E.; Duguet. E. Magnetic nanoparticle design for medical applications. Progress in Solid State Chemistry, 2006, 34, pp. $237-247$.

4. Kirschvink, J.L.; Kobayashi-Kirschvink, A.; Woodford, B.J. Magnetite biomineralisation in the human brain. Proceedings of the National Academy of Sciences, 1992, 89, pp. 7683-7687.

5. Hautot, D.; Pankhurst, Q.A.; Khan, N.; Dobson, J. Preliminary evaluation of nanoscale biogenic magnetite in Alzheimer's disease brain tissue. Proceedings of the Royal Society B (Supplementary), 2003, 270, pp. S62-S64.

6. Goodman L. Alzheimer's disease: A clincopathologic analysis of twenty-three cases with a theory on pathogenesis. Journal of Nervous and Mental Diseases, 1953, 118, pp. 97-130.

7. Murphy, C. J. Biosensors: Plasmons spring into action. Nature Materials, 2007, 6, pp. 259-260.

8. Bratschitsch, R.; Leitenstorfer A. Quantum dots: Artificial atoms for quantum optics. Nature Materials, 2006, 5, pp. 855-856.

9. Reiss, G., Brueckl, H.; Huetten, A.; Schotter, J.; Brzeska, M.; Becker, A.; Kamp, P.B.; Puehler, A.; Wojczykowski, K.; Jutzi, P. Magnetoresistive sensors and magnetic nanoparticles for biotechnology. Journal of Materials Research, 2005, 20(12), pp. 3294-3302.

10. Frankel, R.B.; Blakemore, R.P. Iron Biominerals, Plenum, New York, 1990, 435 p.

11. Balkwil, D.L.; Maratea, D.; Blakemore, R.P. Ultrastructure of a magnetic spirillum. Journal of Bacteriology, 1980, 141, pp. 1399-1408.

12. Cornell, R.M.; Schwertmann, U. The Iron Oxides. Wiley-VCH: Weinheim, 1996, 664 p.

13. Schüler, D. Molecular analysis of a subcellular compartment: the magnetosome membrane in Magnetospirillum gryphiswaldense. Archives of Microbiology, 2004, 181, pp. 1-7.

14. Schüler D. Genetics and cell biology of magnetosome formation in magnetotactic bacteria. Federation of European Microbiological Sciences, Microbiological Reviews, 2008, 32, pp. 654-672.

15. Jones, M.N. Biological interfaces: An Introduction to the Surface and Colloid Science of Biochemical and Biological System. Elsevier: Amsterdam, 1975, 240 p.

16. Xu, Q.; Keiderling, T.A. Effect of sodium dodecyl sulfate on folding and thermal stability of acid-denatured cytochrome c: A spectroscopic approach. Protein Science, 2004, 13, pp. 2949-2959.

17. Büchel, K.H.; Moretto, H.-H.; Woditsch, P. Industrial Inorganic Chemistry. Wiley-VCH: Weinheim, 2000,655 p.

18. Sharrock, M.P.; Bodnar, R.E. Magnetic materials for recording: An overview with special emphasis on particles, Journal of Applied Physics, 1985, 57, pp. 3919-3924.

19. Schumann, D.; Raub, T.D.; Kopp, R.E.; Guerquin-Kern, J-L.; Wu, T-D.; Rouiller, I.; Smirnov, A.V.; Sears, S.K.; Lücken, U.; Tikoo, S.M.; Hesse, R.; Kirschvink, J.L.; Vall, H. Gigantism in unique biogenic magnetite at the Paleocene-Eocene Thermal Maximum. Proceedings of the National Academy of Sciences, 2008, 105(46), pp. 17648-17653.

20. Hou, Y.; Gao, S.; Ohta, T.; Kondoh, H. Towards 3-D Spherical Self-Assembly by Ternary Surfactant Combinations: The Case of Magnetic Nanoparticles. European Journal of Inorganic Chemistry, 2004, 6, pp. 1169-1173.

21. Komelli, A.; Vali, H.; Beveridge, T.J.; Newman, D.K. Magnetosome vesicles are present before magnetite formation and MamA is required for their activation. Proceedings of the National Academy of Sciences, 2004, 101(11), pp. 3839-3844.

22. Andrä, W.; Nowark H. Magnetism in Medicine. Wiley-VCH: Berlin, 1998, 629 p. 